\title{
PENGKREASIAN STIKER VULGAR SEBAGAI TINDAKAN BERMORAL
}

\author{
Oleh: \\ Agus Budi Wahyudi \\ Program Studi Pendidikan Bahasa Indonesia \\ Fakultas Keguruan dan Ilmu Pendidikan \\ Universitas Muhammadiyah Surakarta \\ Agus.B.Wahyudi@ums.ac.id
}

\begin{abstract}
The purpose of this study (a) the presentation of vulgar stickers, and (b) technical pengkreasian vulgar stickers as moral action. Innovation decal sticker vulgar become wise charged educate becomes the moral responsibility of the author stickers, teachers in schools, and communities. It is as a form of moral action that is not potentially omission but potentially significant effect on the handling of the psychosocial condition of the students in the community. Stickers used high school students and posted / attached to the helmets and motorcycles. This research is qualitative research. Descriptive qualitative type of data in the form of words, phrases, sentences contained in the sticker. Researchers pengkreasian sticker though vulgar meaning implement, both from the aspect of semantic nor Mr pragmatic. The object of this research are words or expressions or the negative connotation used vulgar didi child SMA Muhammadiyah Surakarta. The primary data of the unit lingual stickers vulgar and secondary data from the wawancaraData Observation in SMA Muhammadiyah Surakarta and interviews with pupils, the school principal, vice principal field of student affairs, counseling teachers, parking attendants, and community. Mechanical excavation documentation in the form of stickers were sold to high school students. The validity of qualitative data using a triangulation technique that is source triangulation. Techniques of analysis using a unified method. Padan pragmatic method by means of deciding the referent in the form of dialogue partners. In addition to these methods dignakan techniques Descoussin Focus Group Discussion (FGD). Stickers research results used in the form of stickers and stickers vulgar not vulgar. Stickers used vulgar didi son-SMA Muhammadiyah Surakarta potentially affect the morale of the students. The vulgar stickers sticker can dikreasikan be wise. Stickers wise this is socialized to become a rival sticker vulgar. Principals, vice principals, teachers, counseling teachers, and community parties involved in the socialization of sage stickers (stickers pengkreasian results vulgar) this.
\end{abstract}

Keywords: innovation, stickers vulgar and immoral actions.

\begin{abstract}
ABSTRAK
Tujuan penelitian ini (a) penyajian stiker vulgar dan (b) teknik pengkreasian stiker vulgar sebagai tindakan bermoral. Pengkreasian stiker vulgar menjadi stiker bijak yang bermuatan mendidik menjadi tanggung jawab moral si penulis stiker, guru di sekolah, dan masyarakat. Hal ini sebagai wujud tindakan bermoral yang tidak berpotensi pembiaran tetapi berpotensi penanganan yang nyata terhadap kondisi psikososial anak didik di masyarakat. Stiker digunakan anak didik SMA dan dipasang/ditempel di helm dan sepeda motor. Penelitian ini
\end{abstract}


penelitian kualitatif. Kualitatif deskriptif jenis data berupa kata-kata, frasa, kalimat yang terdapat dalam stiker. Peneliti pengkreasian stiker vulgar dengan melaksanakan olah makna, baik dari aspek semantis maupuan pragmatis. Objek penelitan ini berupa kata atau ungkapan berkonotasi negatif atau vulgar yang digunakan anak didi SMA Muhammadiyah di Surakarta. Data primer berupa satuan lingual stiker vulgar dan data sekunder hasil wawancaraData Teknik observasi di SMA Muhammadiyah se-Surakarta dan wawancara dengan anak didik, kepala sekolah, wakasek bidang kesiswaan, guru bimbingan konseling, petugas parkir, dan masyarakat. Teknik dokumentasi berupa penggalian stiker yang terjual ke anak didik SMA. Keabsahan data kualitatif menggunakan teknik triangulasi yaitu triangulasi sumber. Teknik analisis menggunakan metode padan. Metode padan yang pragmatis dengan alat penentu referen yaitu berupa mitra wicara. Selain metode tersebut dignakan teknik Focus Group Descoussin (FGD). Hasil penelitian stiker yang digunakan berupa stiker tidak vulgar dan stiker vulgar. Stiker vulgar digunakan anak didi SMA Muhammadiyah se-Surakarta berpotensi mempengaruhi moral anak didik. Stiker vulgar tersebut dapat dikreasikan menjadi stiker bijak. Stiker bijak inilah yang disosialisasikan sehingga menjadi tandingan stiker vulgar. Kepala sekolah, wakil kepala sekolah, guru, guru bimbingan konseling, dan masyarakat menjadi pihak yang terlibat dalam penyosialisasian stiker bijak (hasil pengkreasian stiker vulgar) ini.

Kata kunci: pengkreasian, stiker vulgar, dan tindakan bermoral.

\section{PENDAHULUAN}

Peredaran stiker vulgar di
masyarakat telah mengganggu
perkembangan moral anak didik. Segi yang
terdeteksi muncul tindakan tak bermoral.
Contoh: kekurangsantunan berbahasa dan
agresivitas yang negatif anak didik.
Tindakan negatif ini perlu ditangani secara
serius. Aktivitas penggalian mengenai
dampak peredaran dan aktivitas
pengkreasian stiker vulgar sehingga tidak
mengganggu anak didik sebagai aset
bangsa.

Stiker vulgar mempengaruhi anak didik ke lini negatif sehingga mereka tidak mengedepankan etika berbahasa, bermunculan sikap acuh terhadap lingkungan, dan kurang bersahabat sesama anak didik serta menganggap enteng eksistensi orang lain.

Tindakan tak bermoral bisa subur dalam kondisi terpengaruh seperti ini. Anak didik terlibat dalam minuman keras, terjebak dalam narkoba, dan tidak menghormati orang lain. Tindakan tak bermoral lainnya bisa berkembang di kalangan anak didik apabila tidak diadakan tindakan bermoral 
yang serta merta bertujuan mengatasi semuanya. Peredaran stiker vulgar perlu dibatasi, pengkreasian stiker vulgar perlu dilakukan dalam rangka mengantisipasi bahasa pengaruh negatif yang ditimbulkan oleh stiker vulgar.

Stiker bijak yang bermuatan nilai pendidikan beredar pula di masyarakat, namun respon anak didik kurang sekali. Artikel ini mengangkat sebagian dari aktivitas penelitian yang sudah dilakukan mengenai stiker vulgar. Ada empat masalah yang telah dianalisis dalam penelitian sebelumnya yaitu berawal dari pemetaan stiker vulgar, peminimalisasian stiker vulgar, pengkreasian stiker vulgar, dan penggalian dampak stiker vulgar (Wahyudi, Yakub, 2016). Oleh karena itu, artikel ini fokus mengenai pengkreasian stiker vulgar sebagai tindakan bermoral. Teknik pengkreasian stiker vulgar ditonjolkan dalam rangka merealisasi upaya pengkreasian.

Masyarakat yang bermoral menjadi harapan, kepribadian masyarakat Indonesia yang luhur menjadi dambaan, dan kesopansantunan berbahasa menjadi modal bagi perkembangan bangsa Indonesia yang luhur di mata dunia. Manfaat inilah yang dicapai secara nyata dalam aktivitas pengkreasian stiker vulgar.

Masalah yang diurakan dalam artikel ini yaitu (a) penyajian stiker vulgar dan (b) teknik pengkreasian stiker vulgar sebagai tindakan bermoral. Pengkreasian stiker vulgar menjadi stiker bijak yang bermuatan mendidik menjadi tanggung jawab moral si penulis stiker, guru di sekolah, dan masyarakat. Hal ini sebagai wujud tindakan bermoral yang tidak berpotensi pembiaran tetapi berpotensi penanganan yang nyata terhadap kondisi psikososial anak didik di masyarakat.

Kajian stiker vulgar (Wahyudi dan Yakub, 2015) ditemukan ragam stiker, yakni vulgar dan tidak vulgar, komonitas, distro (gaya hidup), dan tentang identitas. Pemakaian stiker vulgar berbarengan pemunculan komunitas-komunitas baru, baik bersifat identitas maupun gaya hidup 
(distro). Siker vulgar jadi pilihan anak didik SMA dibanding stiker tidak vulgar.

Tindakan bermoral dicetuskan dalam mengubah stiker vulgar menjadi tidak vulgar dengan memasukkan kesantunan dan nilai potitif ke dalam stiker.

Putra (2015) menganalisis isi kekerasan verbal pada tayangan televisi tayangan Pasbukers di ANTV. Kekerasan verbal terhadap individu penonton tayangan. Adegan kekerasan akan menurunkan sensitifitas penonton. Selain itu hasil penelitian itu, Utami (2015) meneliti tindak kekerasan verbal dan nonverbal oleh guru terhadap siswa SMA Negeri Surakarta tahun 2014/2015. Hasil penelitiannya terdapat fakta tindakan kekerasan dilakukan seorang guru yang memiliki kekuasaan di sekolah. Guru dengan mudah melakukan berbagai kekerasan dengan berlindung di balik tindakan menertibkan anak didik.

Penelitian kekerasan verbal yang dilakukan Agustina (2014) menemukan humor kekersan pada film anak mempengaruhi pola pikir anak. Karakter anak terbentuk karena pengaruh humor kekerasan pada tayangan film. Apabila dikaitkan dengan artikel ini bahwa konsumsi film tersebut mampu memicu lahirnya tindakan tak bermoral anak-anak.

Kekerasan simbolik yang dilakukan Agnibaya (2912) terhadap media massa berkait dengan pemberitaan bonek yang dianalisis sebagai wacana kritis (critical discourse analysis) pada berita media menyimpulkan bahwa wacana yang terdapat dalam berita bonek merupakan konstruksi sosial yang tidak bebas nilai. Bahkan sebagai realisasi kekerasan simbolik yang dilakukan oleh media massa terhadap bonek sebagai objek berita. Kekerasan simbolik ini juga dikaji Suraya (2012) mengenai representasi kekerasan simbolik dalam iklan anak-anak. Hasilnya bahwa iklan anak-anak meneguhkan stereotip peran gender untuk perempuan dan pria. Karakter perempuan dalam iklan anak-anak ditempatkan dalam peran sosial 
sebagai istri, calon istri, dan ibu rumah tangga dengan aktivitas domestik.

\section{METODOLOGI PENELITIAN}

Penelitian ini berjenis penelitian kualitatif. Sesuai pandangan Moleong (2011:6) bahwa penelitian kualitatif adalah penelitian yang bermaksud memahami fenomena tentang apa yang dialami oleh subjek penelitian secara holostik dan dengan cara deskripsi dalam bentuk katakata dan bahsa pada suatu konteks khusus yang alamiah dan dengan memanfaatkan berbagai metode alamiah. Kualitatif deskriptif merupakan jenis data dalam penelitian ini karena berkaitan dengan kata-kata, frasa, kalimat yang terdapat dalam stiker. Oleh karena itu, penelitian ini melaksanakan kreasi stiker vulgar dengan melaksanakan olah makna, baik dari aspek semantis maupuan pragmatis.

Objek penelitan ini berwujud kata atau ungkapan berkonotasi negatif atau vulgar yang menempel pada helm dan sepeda motor milik anak didi SMA Muhammadiyah di Surakarta. Objek penelitian adalah variabel apa yang menjadi titik perhatian di dalam suatu penelitian (Arikunto, 2010:161).

Data primer berupa stiker vulgar yang terdapat dalam stiker -berupa frasa, klausa, kalimat. Adapun data sekunder berupa informasi lisan dari pengguna stiker -anak didik di SMA. Hasil wawancara dimanfatkan membantu penelitia mendeskripsikan makna dan maksud stiker yang mengadung desfemia.

Data disajikan menggunakan teknik observasi di sekolah SMA Muhammadiyah se-Surakarta -khusus di tempat parkir sepeda motor anak didik. Selnjutnya, berwawancara dengan anak didik, kepala sekolah, wakasek bidang kesiswaan, guru bimbingan konseling, petugas parkir, dan masyarakat. Teknik dokumentasi dilaksanakan dengan penggalian stiker yang terjual ke anak didik SMA.

Keabsahan data kualitatif menggunakan teknik triangulasi yaitu 
triangulasi sumber. Peneliti lebih dahulu menentukan ungkapan vulgar dalam stiker yang belum pernah dikaji oleh peneliti yang lain.

Teknik analisis menggunakan metode padan. Metode padan adalah metode yang alat penentunya di luar, terlepas, dan tidak menjadi bagian dari bahasa yang bersangkutan. Metode padan yang pragmatis dengan alat penentu referen yaitu berupa mitra wicara. Selain metode tersebut dignakan teknik Focus

TABEL 1.

PEMETAAN STIKER DI SMA

\begin{tabular}{|c|c|c|c|c|c|c|c|}
\hline No. & $\begin{array}{l}\text { Identitas } \\
\text { Sekolah }\end{array}$ & $\begin{array}{l}\text { Stiker } \\
\text { Vulgar }\end{array}$ & $\begin{array}{l}\text { Tidak } \\
\text { Vulgar }\end{array}$ & Komunitas & Distro & Identitas & Jumlah \\
\hline 1 & $\begin{array}{l}\text { SMA Batik } 1 \\
\text { Surakarta }\end{array}$ & 14 & 10 & 7 & 12 & 9 & 52 \\
\hline 2 & $\begin{array}{lr}\text { SMA } & \text { Al- } \\
\text { Islam } & 1 \\
\text { Surakarta } & \end{array}$ & 27 & 20 & 11 & 11 & 13 & 82 \\
\hline 3 & $\begin{array}{l}\text { SMA } \\
\text { Muhammadi } \\
\text { yah } 1 \\
\text { Surakarta }\end{array}$ & 40 & 24 & 20 & 4 & 4 & 82 \\
\hline
\end{tabular}


Tabel 1 menggambarkan pemetaan stiker vulgar, tidak vulgar, komunitas, distro, dan mengenai identitas. Selain itu, masalahan baru mengenai komunitas baru, baik bersifat identitas maupun gaya hidup (distro) di SMA.

Permasalahan utama mengenai stiker vulgar mendominasi dari masing-masing SMA terlihat pada pemetaan di bawah ini.

\section{(a) Contoh Stiker Vulgar}

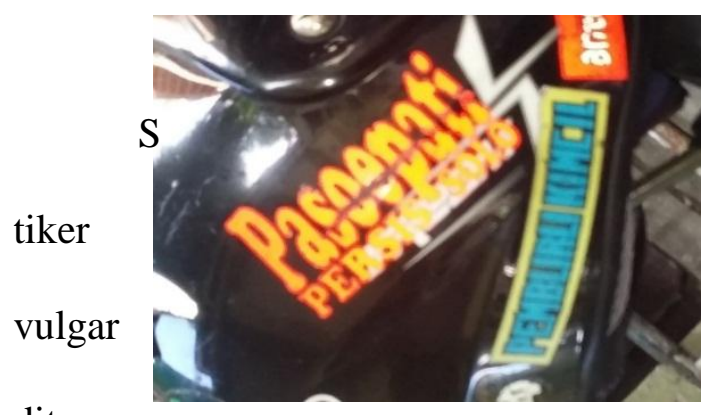

ditem

ukan di helm milik siswa SMA Al Islam Surakarta. Satuan lingual berbentuk frasa, yaitu "pemburu kimcil". Frasa ini terdiri kata pemburu'orang yang kerjanya berburu' dan kimcil. Kata kmcil" akronim dari frasa "kemaluan cilik" (dalam bahasa Indonesia berarti "kemaluan wanita yang kecil") yang berarti remaja dibawah umur yang berperilaku seperti halnya wanita tunasusila.
Stiker vulgar "pemburu kimcil" berarti 'orang yang senang memburu remaja yang berperilaku seperti halnya wanita tunasusila'. Stiker ini vulgar karena kandungan makna dalam frasa tersebut tidak pantas diungkapkan anak didik SMA. Perhatikan contoh berikut.

Satuan lingual "kimcil gila" di

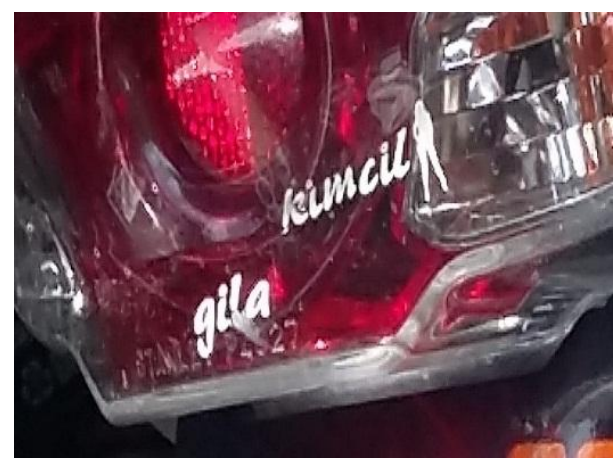

bagian lampu belakang sepeda motor. merupakan akronim dari frasa "kemaluan cilik" (dalam bahasa Indonesia berarti "kemaluan wanita yang kecil") yang berarti remaja dibawah umur yang berperilaku seperti halnya wanita tunasusila. Kata "gila" berarti 'kurang baik ingatan'. Stiker ini vulgar karena mengandung pisuhan, menyinggung dan mengganggu harga diri wanita. 
Contoh stiker vulgar di SMA Al Islam Surakarta dan SMA Muhammadiyah 1 Surakarta. "Cinta monyet (cintanya udah pergi, tinggal monyetnya lagi baca tulisan ini!". Cinta monyet (hubungan asmara antarremaja) merupakan hal yang lumrah, begitu pula dengan patah hati. Satuan lingual frasa "cintanya udah pergi". Maka yang tertinggal hanya "monyet"nya. Monyet maksudnya 'seseorang yang membaca tulisan stiker'Makna stiker itu penghinaanterhadap setiap orang yang membaca stiker.

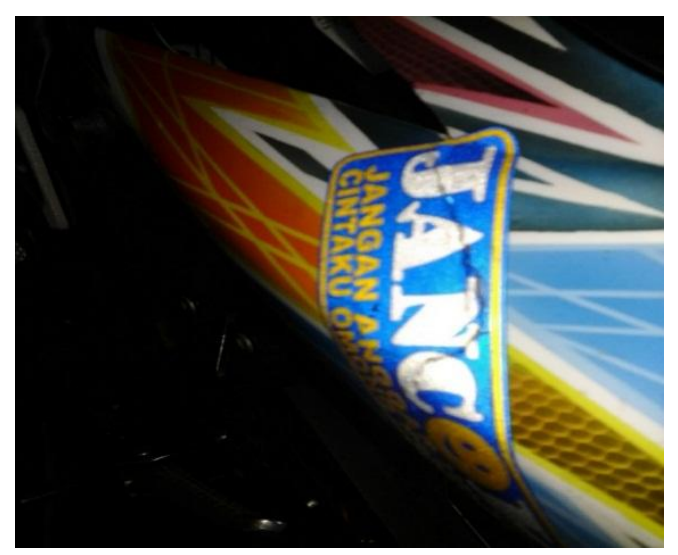

Stiker Vulgar

Satuan lingual "Jancok (jangan anggap nilai cintaku omong kosong)”. Stiker ini ditemukan di SMA Batik 1 Surakarta berbentuk akronim. Pesan stiker ini adalah agar seseorang yang dicintainya tidak menganggap cintanya hanya sekadar omong kosong atau bualan.Cinta pemilik stiker ini dikatakan sebagai cinta yang sungguhsungguh. Makna stiker ini positif, tetapi akronim "jancok" kepanjangan dari kalimat “jangan anggap nilai cintaku omong kosong” berwujud pisuhan untuk mengungkapkan kejengkelan atau kemarahan seseorang kepada orang lain.

Berkaitan dengan banyaknya stiker vulgar dilingkungan SMA Batik 1 Surakarta dilakukan konfirmasi/ wawancara bersama bapak Bambang Isniyanto selaku pengampu mata pelajaran bahasa Indonesia. Beliau memaparkan banyaknya stiker tersebut selama ini perlu adanya tindakan preventif dan masih luput dari ketelitian mengenai fokus pengawasan. Banyaknya jumlah stiker vulgar disebabkan karena lingkungan yang memengaruhi. Ketika kami konfirmasi mengenai pengaruh stiker vulgar di 
lingkungan pembelajaran dirasa ada pengaruhnya berkaitan dengan bahasa yang digunakan siswa dalam berkomunikasi dengan guru maupun teman sebaya.

Meminimalisasi Peredaran Stiker Vulgar di Lingkungan Pelajar SMA se-Surakarta

Stiker vulgar memiliki dampak negatif terhadap perkembangan moral anak didik Dampak tersebut secara tidak langsung dapat dilihat dari perubahan perilaku ataupun bahasa yang dipakai dalam berkomunikasi. Kecenderungan perubahan perilaku remaja tersebut salah satunya dipengaruhi oleh pemerolehan bahasa yang mereka dapatkan. Berdasarkan hasil pengamatan di SMA Batik 1 Surakarta, SMA Al-Islam, dan SMA Muhammadiyah 1 Surakarta kecenderungan mereka menempelkan stiker pada helm ataupun beberapa bagian sepeda motor disebabkan rasa iseng, ekspresi diri, dan pesan kepada pembaca.

Selain itu, ketika disinggung mengenai asal mereka mendapatkan stiker tersebut dibeli melalui penjual stiker. Mengenai peredaran stiker baik vulgar ataupun tidak vulgar perlu adanya upaya meminimalisasinya. Upaya peminimalisasian salah satunya diwujudkan dengan cara pengkreasian stiker vulgar.

Teknik Pengkreasian Stiker Vulgar Menjadi Stiker Bijak

Pengkreasian stiker yang inovatif, kreatif, dan membangun moral yang penting dilakukan. Masalah utama yang dihadapi penulis stiker adalah karena sedikitnya pembendaharaan bahasa. Oleh karena itu, pengkreasian ini menjadi langkah konkret pencegahan peredaran stiker vulgar.

Penulis, penjual, dan produksen stiker menyambut baik diskusi yang dilaksanakan. Ketika dikonfirmasi, dinyatakan bahwa stiker yang dijual dan diproduksi tidak vulgar semua ada yang bijak. Stiker bijak mengandung motivasi dan kutipan pendapat seseorang. Namun 
demikian, stiker vulgar diakui banyak diminati anak didik SMA. Bahasa seharihari dekat dengan anak didik, sering muncul di media, di percakapan sehari-hari, bahasa yang "madolke".

Berikut variasi hasil bentukan dari data stiker vulgar.

Cinta GW Sama Loe sama besar kepadanya

Makna stiker 'cinta seseorang kepada pacarnya ternyata sama besar kepada orang lain'. Jadi, cinta yang mendua, yakni samasama cinta antar makhluk. Hal itu ditandai penggunaan klitik -nya pada kepadanya. Klitik -nyadapat disubstitusi misalnya dengan teman loe sehingga dihasilkan stiker hipotetis semacam (1a) berikut ini.

(1a) Cinta GW sama Loe sama besar kepada teman loe

Stiker hipotetis (1a) masih belum berubah maknanya, yakni cinta yang diduakan. Keduanya menunjuk pada makhluk ciptaan Allah. Adapun stiker hipotetis (1b) hingga (1e) berikut acuannya sudah bergeser, yakni cinta makhluk (: manusia) kepada Sang Khalik. Ada penggantian pronominal - nya yang mengacu pada makhluk dengan $-\mathrm{Nya}$ yang mengacu pada Sang Khalik.

(1b) Cinta GW sama Loe tak sebesar cinta GW kepada-Nya

(1c) Cinta GW kepada Loe tak sebanding cinta-Nya pada kita

(1d) GW cinta pada Loe, tapi GW lebih cinta kepada-Nya

(1e) GW cinta pada Loe karena

\section{GW penuhi cinta-Nya}

\section{Kalah Pinter kalah Bagus kalah Sugih}

Makna stiker (2) di atas adalah seseorang yang kalah dalam segala hal berkaitan dengan fisik. Ungkapan kalah secara harfiah menyatakan sebuah keadaan tidak menang atau kalah dalam bersaing. Ungkapan tersebut diulang sampai tiga kali yang bisa diartikan kekalahan berulangulang dari orang tersebut. Tulisan Pinter,Bagus, dan Sugih berasal dari bahasa jawa yang berarti pintar, tampan, dan kaya. 
Jadi secara utuh ungkapan tersebut memiliki maksud seseorang yang kalah dalam segala hal, baik dari segi kepintaran, ketampanan, dan kekayaan. Selain itu, ungkapan tersebut menyiratkan pesimistis dan mudah menyerah dalam segala hal. Variasi stiker tersebut dapat dibentuk dengan beberapa hasil kreasi.

(2a) kalah Pinter kalah Bagus kalah Sugih, tapi menang Iman dan Taqwanya

(2b) kalah pinter, bagus, lan sugih, nanging menang imane

Kreasi bentukan stiker (2a) menumbuhkan sikap optimistis yang dibangun oleh seseorang meskipun kalah dalam hal kepintaran, ketampanan, dan kekayaan, tetapi ia menang dalam keimanan dan ketaqwaan yang jauh lebih penting. Selain itu, bentukan kreasi stiker (2b) meskipun memiliki makna yang kurang lebih sama dengan makna (2a), tetapi secara makna tidak kalah berulang-ulang karena penulisan ungkapan kalah ditulis satu kali saja dan adanya variasi penggunaan bahasa jawa. Selain contoh kreasi di atas, dapat pula beberapa hasil kreasi lain.

Motor Loe Bagus Muke Loe Enggak!

Makna stiker (3) di atas adalah ungkapan ejekan yang dilakukan oleh penempel stiker kepada pembaca. Hal itu dapat dilihat dari adanya ungkapan Muke Loe Enggak yang bermakna wajah yang tidak sebagus motornya. Adanya ungkapan wajah yang tidak sebagus motornya termasuk salah satu ungkapan vulgar dan bisa saja si pembaca stiker merasa tersinggung atas tulisan tersebut sehingga bisa menimbulkan masalah lain yang lebih luas. Ungkapan Motor Loe Bagus merupakan salah satu ungkapan dialek Jakarta atau betawi yang dianggap bahasa gaul oleh beberapa kaum muda. Secara utuh tulisan stiker tersebut dapat dikreasikan menjadi beberapa bentuk.

(3a) Motor Loe Bagus Muke Loe Enggak Jauh Beda

(3b) Motor dan Muke Loe Sama Bagusnya 
Kreasi bentukan stiker (3a) mengungkapkan adanya pujian terhadap motor yang dimiliki pembaca tulisan stiker dan sekaligus memuji wajah yang tidak jauh beda dengan motornya. Kreasi tersebut tidak banyak menubah tulisan, tetapi hanya menambahkan beberapa kata sehingga menjadi kesatuan makna yang lebih halus. Selain itu, bentukan kreasi stiker (3b) memiliki tulisan yang lebih efektif dan mudah dipahami. Makna yang diungkapkan langsung mengungkapkan motor yang dimiliki pembaca dan wajah pembaca samasama bagus.

\section{Cukup kenal kowe..!}

Makna stiker (4) di atas adalah ungkapan seseorang yang hanya mau kenal satu orang saja tanpa mau kenal yang lainnya. Ungkapan tersebut diperkuat dengan adanya tanda seru (!) pada bagian akhir tulisan sebagai penguat ungkapan. Hal itu dianggap kurang baik apabila diterapkan oleh seseorang karena hidup dalam suatu masyarakat seharusnya menyayangi Allah dan masyarakat juga. Variasi tulisan ungkapan tersebut dapat dibentuk menjadi beberapa kreasi berikut ini.

(4a) Tak cukup kenal Kowe..! penting, diriNya

(4b) Tak cukup kenal Kowe..! Nanging konco liyane

Hipotetis pada (4a) mengemukakan pengenalan yang tidak hanya cukup satu orang saja atau mengarah kepada manusia, melainkan lebih penting mengenal pada Tuhan. Selain itu, ungkapan tersebut memberikan arahan untuk lebih mengenal selain satu orang saja. Ungkapan (4b) dikreasikan dengan tujuan untuk lebih bersosial mengenal teman lainnya selain satu orang yang dimaksud.

\section{I $\odot$ Ndasmu}

Makna pada stiker di atas mengandung ungkapan pisuhan. Hal tersebut ditunjukkan dari kata Ndasmu yang dalam bahasa Jawa berarti 'kepalamu'. Ungkapan ini bermakna kasar jika ditujukan dalam 
berkomunikasi dengan orang lain. Selain itu, ungkapan tersebut bersifat sarkasme dan kurang tepat apabila dibaca oleh anak kecil. Adapun alternatif stiker adalah sebagai berikut.

\section{(5a) I $\odot$ akhlakmu \\ (5b) I $\odot$ U karena Allah \\ (5c) I $\varnothing$ Allah}

Alternatif stiker (5a) dan (5b)

menunjukkan makna kecintaan seseorang kepada orang lain. Adapun pada alternatif (5c) menunjukkan makna cinta yang lebih tinggi derajatnya, yaitu kecintaan seseorang kepada Allah.

Muda Berbahaya

$$
\text { Ungkapan pada stiker }
$$
mengandung makna yang menunjukkan agresivitas seorang anak muda. Hal ini ditunjukkan dari kata berbahaya. Adapun alternatif stiker yang lebih mendidik sebagai berikut. (6a) Muda Berbudaya, supaya tidak berbahaya

(6b) Muda Beretika, jauh dari bahaya

(6c) Muda Beragama, terhindar dari bahaya

(6d) Muda ituTidak Berbahaya

Alternatif stiker pada (6a), (6b), dan

(6c) menunjukkan nilai-nilai motivasi kepada kaum remaja muda. Bila alternatif (6a) menunjukkan semangat kaum muda untuk mencintai dan melestarikan nilai-nilai budaya lokal, alternatif (6b) menunjukkan karakter kaum muda yang beretika dan menjunjung tinggi nilai-nilai kesopanan. Adapun alternatif (6c) menunjukkan karakter anak muda yang berpedoman pada nilai-nilai ketuhanan. Alternatif menunjukkan adanya ungkapan seorang jiwa muda itu sebenarnya tidak berbahaya apabila bisa dikendalikan

$100 \%$ milik pribadi

Makna pada data (7) menunjukkan adanya karakter seorang yang serakah dan 
antisosial pada sesama. Hal ini terlihat dari ungkapan yang menunjukkan makna kepemilikan yang hanya dimiliki oleh pribadi seorang individu. Adapun stiker ini menunjukkan kecintaan yang berlebihan terhadap sisi duniawi. Alternatif stiker yang lebih bernilai mendidik sebagai berikut.

(7a) $100 \%$ milik pribadi

\section{titipanNya}

(7b) TitipanNya, $100 \%$ milik pribadi

Alternatif stiker pada (7a) dan (7b) sudah berubah maknanya. Pada alternatif tersebut ditunjukkan makna keyakinan seseorang bahwa semua yang ia miliki hanyalah titipan dan akan kembali kepada Allah sebagai pemilik hakiki. Karakter yang ditimbulkan pada alternatif stiker ini akan muncul sikap yang dermawan dan daya sosial yang tinggi terhadap sesama.

Get away from me!!!

Stiker (8) menunjukkan makna sikap yang juga antisosial terhadap orang lain. Hal ini terlihat dari arti ungkapan tersebut dalam bahasa Indonesia yang berarti 'menjauhlah dariku'. Stiker ini memiliki maksud yang baik jika dikaitkan dengan kendaraan lain yang harus menjaga jarak dengan pengendara yang memiliki stiker ini. Namun, ungkapan ini tetap mencerminkan sikap yang antisosial disamping sikap yang mementingkan keselamatan. Adapun alternatif stikernya sebagai berikut.

(8a) Get away from me, if you use drug.

(8b) Get away from me, if you far from God.

Pada alternatif stiker (8a) terlihat pergeseran makna yang lebih positif dan bernilai mendidik bagi remaja. Hal ini terlihat dari makna stiker yang menunjukkan imbauan bagi remaja untuk menjauhi dirinya jika seseorang tersebut memakai narkoba. Adapun pada alternatif (8b) menunjukkan makna stiker yang mengungkapkan penegasan untuk menjauhi maksiat dan hal- 
hal yang melanggar norma dan lebih mendekatkan kepada Allah.

Warning! Masih galau belum bisa move on

Makna yang diungkapkan pada stiker

(6) menunjukkan keadaan seseorang yang tidak bersemangat. Stiker ini tidak dinilai mendidik dan justru akan menimbulkan sugesti kepada pembaca untuk tidak bersemangat pula. Padahal, para remaja harus memiliki sikap aktif untuk pengembangan diri mereka. Adapun alternatif stikernya adalah sebagai berikut.

(9a) Warning! Anti galau, semangat move on

(9b) Warning! Anti galau, selalu ingat Allah untuk move on

Pada alternatif stiker ditunjukkan adanya ajakan semangat bagi pembaca untuk tidak berlama-lama larut dalam situasi tidak nyaman. Adapun alternatif (9b) menunjukkan ajakan sekaligus sugesti untuk selalu mengingat Allah dan segala masalah dikembalikan kepada Allah.
Melalui stiker ini diharapkan kepada pembaca untuk termotivasi semangat dan sisi ketuhanannya.

\section{4 jam pria beralkohol}

Makna pada stiker (10) jelas mengungkapkan cerminan kepribadian yang negatif. Pada stiker tersebut terlihat bahwa pria tersebut adalah seorang pecandu alkohol. Hal ini jelas membawa pengaruh negatif pula bagi perkembangan psikologi remaja yang notabene masih mencari jati diri, mementingkan ego, dan belum bisa memilah secara baik hal mana yang bermanfaat bagi mereka. Untuk itu diperlukan alternatif stiker yang lebih mendidik dan memotivasi sebagai berikut.

(10a) 24 jam pria berprestasi, tanpa beralkohol

(10b) 24 jam pria berlogika dan tak beralkohol

Pada alternatif (10a) dan (10b) terlihat makna negatif yang telah bergeser pada makna yang lebih positif. Pada alternatif (10a) terlihat adanya motivasi bagi pembaca, 
khususnya remaja, untuk terus pembaca (manusia) yang diolok-olok

mengembangkan diri dan berprestasi sesuai

minat dan bakat mereka. Pada stiker tersebut

terlihat ajakan untuk mengisi hari-hari

mereka dengan kegiatan yang memacu prestasi.

Alternatif (10b) menunjukkan motivasi bagi remaja untuk mulai berpikir akan halhal yang lebih bermanfaat bagi diri mereka. Pada stiker ini terlihat ajakan bagi remaja untuk tidak mementingkan ego dan kesenangan sesaat saja, tetapi lebih kepada dampak jangka panjang bagi masa depan mereka terkait hal yang mereka lakukan saat ini.

Cinta monyet. Cintanya sudah pergi tinggal monyetnya lagi baca tulisan ini

Makna pada stiker (11) menunjukkan adanya ungkapan yang menghina pembaca. Hal ini terlihat dari klausa "monyetnya lagi baca tulisan ini”. Pada penggalan itu, yang dimaksud 'monyet' jelas bukan monyet bermakna 'binatang', tetapi lebih kepada sebagai monyet. Stiker ini jelas jauh dari nilai sopan-santun dan etika berkomunikasi. Adapun alternatif stiker yang ditawarkan adalah sebagai berikut.

(11a) Cinta monyet. Monyetnya sudah pergi, tinggal cintanya hanya untuk Allah.

(11b) Lagi baca tulisan ini! Monyet sudah pergi, tinggal Allah yang ada di hati ini

Pada alternatif tersebut terlihat bahwa makna yang terkandung sudah bernilai positif. Maksud yang terkandung pada alternatif stiker adalah ajakan untuk lebih mencintai Allah dibanding dengan cinta terhadap sesama. Melalui alternatif stiker ini diajarkan kepada remaja untuk memahami nilai-nilai ketuhanan.

Ragagas!!!

Pada stiker (12), ungkapan 'Ragagas!!!' memiliki makna yang luas penafsirannya. Adapun penggunaan tiga tanda seru di belakang kata tersebut 
menggambarkan intonasi yang tinggi. Salah satu penafsiran yang paling dekat dengan remaja adalah cerminan sikap mereka yang masih berada diluar kendali dan tidak memikirkan baik-buruk dampaknya ketika mereka melakukan suatu hal. Ada baiknya jika ungkapan pada stiker ini diperluas agar jelas maknanya dan bernilai motivasi atau ajaran yang bermanfaat bagi perkembangan remaja. Adapun alternatif yang disarankan sebagai berikut.

(12a) Ragagas pacaran, fokus kuliah (12b) Ragagas alkohol, fokus Al-Quran Alternatif stiker (12a) dan (12b) menunjukkan pergeseran makna yang lebih positif. Makna pada ungkapan (12a) sekaligus menunjukkan ajakan bagi kaum remaja untuk memfokuskan diri pada perkuliahan. Adapun pada data (12b) mengajak remaja untuk menjauhi alkohol. Nilai positif yang ditawarkan adalah agar remaja dekat dengan Al-Quran. Gila kimcil
Makna pada stiker (13) tersebut bernilai disfemia. Kimcil memiliki makna yang sama dengan 'pelacur'. Secara keseluruhan, makna frasa tersebut adalah seorang yang sangat menyukai kimcil. Dengan kata lain, orang tersebut dekat dengan pergaulan yang bebas. Adapun alternatif stiker nyang ditawarkan sebagai berikut.

\section{(13a) Gila belajar \\ (13b) Gila prestasi}

Alternatif stiker (13a) dan (13b) sudah bergeser makna disfemianya. Pada alternatif stiker tersebut, pembaca dimotivasi untuk memiliki semangat belajar, berprestasi, dan mengembangkan diri. Bertolak belakang dengan makna stiker (13) yang membawa pola pikir pembaca untuk menuju ke aras yang negatif.

\section{Galau}

$$
\begin{aligned}
& \text { Makna pada stiker } \\
& \text { menggambarkan perasaan gundah yang } \\
& \text { dialami remaja karena sebuah permasalahan. } \\
& \text { Stiker ini tidak bermanfaat bagi pembaca. }
\end{aligned}
$$


Hal ini disebabkan tidak adanya nilai pendidikan atau motivasi yang didapat dari stiker tersebut. Adapun alternatif stiker yang lebih bermakna positif sebagai berikut.

(14a) Galau, gak lah yau

(14b) Anti galau

Pada alternatif stiker (14a) dan (14b) terlihat pergeseran makna dan adanya nilai semangat untuk remaja. Melalui stiker ini, remaja diajak untuk jauh dari rasa galau yang menghambat kreativitas bagi mereka.

\section{Let's gage ngopo wae}

Makna yang terkandung dari stiker di atas adalah mengajak pembaca untuk melakukan aktivitas apa pun. Tidak dijelaskan penekanan aktivitas yang dilakukan. Maka, penafsiran yang memungkinkan ditafsirkan bagi remaja adalah melakukan aktivitas yang mengutamakan kesenangan semata. Hal ini terlihat dari tidak adanya kontrol yang diajarkan kepada remaja. Adapun alternatif stiker yang ditawarkan sebagai berikut. (15a) Let's gage ngaji wae

(15b) Let's gage sekolah wae

Makna pada alternatif (15a) dan (15b) sudah mengalami bergeseran makna dengan ajakan kepada pembaca untuk melakukan aktivitas yang jelas. Pada alternatif (15a), makna yang terkandung adalah ajakan kepada pembaca untuk beribadah mengaji dan mempelajari nilainilai ketuhanan. Dari hal tersebut terlihat nilai keagamaan ditonjolkan untuk memotivasi pembaca agar dekat dengan Tuhan. Adapun alternatif (15b) mengajak pembaca, khususnya remaja, untuk memiliki semangat dan fokus untuk dunia pendidikan mereka. Dengan begini, alternatif stiker yang ditawarkan akan lebih jelas maknanya dan bernilai mendidik bagi pembaca.

Pelan-pelan saja jaga jarak Anda (dengan gambar hewan anjing)

Pada stiker (16) makna yang diungkapkan pada dasarnya sudah baik. Adapun maksudnya adalah imbauan agar 
pengendara motor lebih berhati-hati dalam berkendara. Namun, stiker tersebut bernilai disfemia karena gambar yang ditampilkan adalah gambar anjing.

(16a) Pelan-pelan saja jaga jarak Anda (tanpa gambar hewan anjing)

(16b) Anda pelan-pelan dan jaga jarak (tanpa gambar hewan anjing)

Tulisan (16a) memberikan arahan untuk mengemudikan secara hati-hati dan menjaga jarak dengan bagian damper kendaraan. Ungkapan tersebut dirasakan lebih santun dan memiliki makna yang sopan tanpa adanya gambar. Adapun (16b) dikreasikan dengan membalikkan tiap kata, tetapi tidak menghilangkan maknanya.
Kamu'. Walaupun bentuk ini dapat dikatakan kreatif tetapi akronim ASU mengandung nilai disfemia. Asu dalam bahasa Jawa berarti 'anjing' dalam bahasa Indonesia. Adapun alternatif stiker yang ditawarkan sebagai berikut.

\section{(17a) AYU (Aku saYang kamU)}

Alternatif stiker (17a) masih mempertahankan kreasi dalam bentuk akronim. Hanya saja bentuk akronimnya diganti dengan kosakata yang lebih sopan dibanding dengan akronim 'ASU'. Akronim 'AYU' diambil dari huruf 'A' pada kata pertama 'Aku', huruf ' $\mathrm{Y}$ ' diambil dari huruf ketiga kata 'sayang', sedangkan huruf ' $U$ ' diambil dari huruf terakhir kata 'kamu'. Adapun dalam bahasa Jawa, kata 'ayu' berarti 'cantik'. Jelas memiliki makna yang lebih positif dibanding kata 'asu'.

\section{ASU (Aku Sayang Kamu)}

Stiker pada data (17) memanfaatkan bentuk akronim agar telihat lebih kreatif. Akronim ASU merupakan bentuk singkat yang terbentuk dari kalimat 'Aku Sayang
Tindakan Bermoral: Wujud Penyosialisaian Stiker Bijak

Pihak-pihak yang bertanggung jawab dalam tindakan bemoral yang berwujud 
sosialisasi stiker bijak antara lain: kepala sekolah, wakil kepala sekolah bidang kesiswaan, guru, guru bimbingan konseling, masyarakat -si penulis stiker dan orang tua.

Kepala sekolah sebagai pimpinan lembaga pendidikan mengagendakan peminimalisasian beredarnya stiker vulgar dan menggairahkan peredaran stiker vijak di sekolah. Kepala sekolah dibantu wakil kepala sekolah bidang kesiswaan dalam rangka pelaksanaan sosialisasi stiker bijak. Guru memiliki tugas mendorong anak didik menghidnari pemakaian stiker vulgar dan mengadakan pilihan ke stiker bijak. Guru bimbingan konseling selalu memantau peredaran stiker di sekolah, dan mengarahkan pemilihan pemakaian stiker bijak.

Penulis stiker merasa bahwa dirinya turut bertanggung jawab sebagai penjaga moral anak didi di sekolah, maka tindakan menghasilkan stiker vulgar dihentikan. Masyarakat -orang tua meneliti kembali perilaku anak dalam menempel stiker baik di helm maupun sepeda motor. Apabila diciptakan gerakan sosialisasi stiker bijak ini secara kompak, maka tidnakan negatif anak didik dapat dikembangtumbuhkan secara baik.

\section{PENUTUP}

Stiker digunakan anak didik SMA dan dipasang/ditempel di helm dan sepeda motor. Stiker yang digunakan berupa stiker tidak vulgar dan stiker vulgar. Stiker vulgar digunakan anak didi SMA Muhammadiyah se-Surakarta berpotensi mempengaruhi moral anak didik.

Stiker vulgar tersebut dapat dikreasikan menjadi stiker bijak. Stiker bijak inilah yang disosialisasikan sehingga menjadi tandingan stiker vulgar. Kepala sekolah, wakil kepala sekolah, guru, guru bimbingan konseling, dan masyarakat menjadi pihak yang terlibat dalam penyosialisasian stiker bijak (hasil pengkreasian stiker vulgar) ini. 
Karseno. 2013. "Analisis Pemakaian Disfemia pada Komentator Sepakbola Liga Indonesia di ANTV". Skripsi. Surakarta: Fakultas Keguruan dan Ilmu Pendidikan UMS.

Moleong, Lexy. 2011. Metodologi Penelitian Kualitatif. Bandung: Rosdakarya.

\section{DAFTAR PUSTAKA}

Agnibaya, Rangga. 2012. "Kekerasan Simbolik Media Massa pada Pemberitaan Bonek: Critical Discourse Analysis Berita Media". Tesis. Program Linguistik: Fakultas Ilmu Budaya UGM.

Agustina, Endah. 2013. "Humor Kekerasan Film Anak-anak Televisi Indonesia dan Pengaruhnya terhadap Pembentukan Pola Pikir Anak-anak". Jurnal UNIVERA. Vol.2 No.2 Halaman. 7-25.

Aminuddin. 2008. Semantik: Pengantar Studi tentang Makna. Bandung: Sinar Baru Algensindo.

Arikunto, Suharsimi. 2010. Prosedur Penelitian. Jakarta: Rineka Cipta.

Depdiknas. 2008. Kamus Besar Bahasa Indonesia. Jakarta: Gramedia.

Djajasudarma, T. Fatimah. 1999. Semantik 2: Pemahaman Ilmu Makna. Bandung: PT Refika Aditama.

Istiana, Rahayu Nur. 2006. "Analisis Pemakaian Disfemia pada Rubrik Gagasan Surat Kabar Solopos". Skripsi. Solo: UNS.
Putra, Syarif Ady. 2015. "Analisis Isi Kekerasan Verbal pada Tayangan Pesbukers di ANTV". E-Jurnal Ilmu Komunikasi. Volume 3, Nomor 1, Halaman 281-294.

Rifai, Ahmad. 2012. "Analisis Disfemia dalam Tajuk Rencana Koran Kompas Edisi Januari 2011 serta Implikasinya dalam Pembelajaran Bahasa dan Sastra Indonesia di SMA". Skripsi. Surakarta: Fakultas Keguruan dan Ilmu Pendidikan UMS.

Suraya. 2013. "Representasi Kekerasan Simbolik dalam Iklan Anak-anak". Jurnal Komunikator. Vol.5, No.1, Halaman 40-52.

Utami, Anari Wahyu. 2015. "Studi Mengenai Tindak Kekerasam Verbal dan Nonverbal oleh Guru terhadap Siswa SMA Negeri di Surakarta Tahun Ajaran 2014/2015". Skripsi. Surakarta: UNS.

Wahyudi, Agus Budi dan Yakub Nasucha. 2015. "Pemetaan, Peminimalisasian, Pengkreasian, dan Penggalian Dampak Stiker Vulgar di Lingkungan Pelajar SMA Surakarta". Laporan Penelitian Unggulan Perguruan Tinggi Tahun I. Dibiayai Koordinasi Perguruan Tinggi Swasta Wilayah VI Kementerian Pendidikan dan Kebudayaan sesuai dengan Surat Perjanjian Pelaksanaan Hibah

Penelitian 
No.007/K.6/KM/SP2H/Penelitian_BA

TCH-1/2015, 30 Maret 2015.

Bahastra, Oktober 2016, Volume XXXVI, Nomor 1 